\section{BMJ Open} Ophthalmology

\title{
Role of hypertension as a risk factor for open-angle glaucoma: a systematic review and meta-analysis
}

\author{
Ririn Nislawati, ${ }^{1}$ Ahmad Taufik Fadillah Zainal (D) ${ }^{2}$ Abrar Ismail, ${ }^{1}$ Noro Waspodo, ${ }^{1}$ \\ Firdaus Kasim, ${ }^{3}$ Andi Muh Aunul Khaliq Gunawan ${ }^{2}$
}

\begin{abstract}
To cite: Nislawati $R$, Taufik Fadillah Zainal A, Ismail A, et al. Role of hypertension as a risk factor for open-angle glaucoma: a systematic review and meta-analysis. BMJ Open Ophthalmology 2021;6:e000798. doi:10.1136/ bmjophth-2021-000798
\end{abstract}

Received 10 May 2021 Accepted 5 September 2021

D Check for updates

(C) Author(s) (or their employer(s)) 2021. Re-use permitted under CC BY-NC. No commercial re-use. See rights and permissions. Published by BMJ.

${ }^{1}$ Department of Ophthalmology, Hasanuddin University,

Makassar, Indonesia

${ }^{2}$ Faculty of Medicine,

Hasanuddin University,

Makassar, Indonesia

${ }^{3}$ Department of Community

Medicine, Hasanuddin

University, Makassar, Indonesia

Correspondence to Mr Ahmad Taufik Fadillah Zainal; ahmadtaufik2014004@gmail. com

\section{ABSTRACT}

Glaucoma is the leading cause of irreversible blindness. It is estimated that as many as 3.2 million people worldwide experience blindness due to glaucoma, including openangle glaucoma (OAG). Until now, there is no definite mechanism related to the incidence of OAG. However, increased intraocular pressure (IOP) is considered to be the most important risk factor. Several current studies show that there is a significant relationship between hypertension (HTN) and IOP. In particular, several epidemiological studies have shown that an increase in systemic blood pressure (BP) is associated with an increase in IOP. However, several studies report that high BP provides a protective effect at a young age against the incidence of OAG. Therefore, this literature aims to explore the effect of HTN on the incidence of OAG. In this review, search for the literature using keywords that match the topic, then a gradual screening was carried out with the predetermined eligibility criteria. From 3711 studies, 16 studies matched the criteria having a total sample size of 72212 and then a quantitative meta-analysis was conducted. The results showed a risk ratio of $1.69(95 \%$ Cl 1.50 to 1.90) in the HTN group. However, from our qualitative synthesis, we found that people who have an unstable diastolic blood pressure (DBP), either high or low, are both able to increase the risk of OAG events. In conclusion, we found that HTN was able to increase the risk of $O A G$ and $D B P$ instability, whether high or low, can also increase the risk of OAG incidence.

\section{INTRODUCTION}

Glaucoma is the leading cause of irreversible blindness worldwide. According to WHO report, it was estimated that there are 3.2 million people who have experienced blindness due to glaucoma. ${ }^{1}$ Glaucoma is generally defined as an optic neuropathy characterised by damage to the retinal ganglion cells (RGCs) in the inner core layer associated with structural damage to the optic nerve and loss of field of view. ${ }^{2}$ Based on the morphology of angular iridocorneal, glaucoma is divided into the following two types: open-angle glaucoma (OAG) and angle-closed glaucoma.

Until recently, the pathogenesis of OAG was not fully understood. Increased intraocular pressure (IOP) is considered the most critical risk factor. ${ }^{4}$ IOP is the pressure generated by the contents of the eyeball against the eyeball wall. The balance between the production of aqueous humour by the ciliary corpus and drainage through the two meshwork and uveoscleral trabecular pathways then empties into the episclera veins, which is a mechanism that maintains the IOP stability. ${ }^{45}$ Pressure and strain on the lamina cribrosa induced by an increase in IOP cause compression, deformation and remodelling, which results in damage to RGC axons. ${ }^{4} 6$

Maintaining the stability of IOP is a challenge to answer the problem of blindness that exists around the world, especially those caused by glaucoma. Some of the results of this study indicate that there is a significant relationship between hypertension (HTN) and IOP, which is a risk factor for the occurrence of primary open-angle glaucoma (POAG). ${ }^{7}$ In particular, several epidemiological studies have reported that an increase in systemic blood pressure (BP) is associated with a slight increase in IOP. ${ }^{8}$ This is because the increase in BP increases episclera venous pressure so that the aqueous clearance (excretion of aqueous humour) will decrease, which will cause an increase in IOP. ${ }^{9}$ However, until recently, the relationship between $\mathrm{BP}$ and the incidence of glaucoma is still being debated. Some studies report that there is no correlation between systemic BP with IOP and the incidence of glaucoma. ${ }^{10}$ Even several other studies reported that in younger patients, HTN gave a protective effect by increasing the ocular perfusion pressure (OPP) or eye perfusion pressure against the incidence of glaucoma. $^{11}$

Previously, Zhao et $a l^{12}$ conducted a systematic review and meta-analysis on the same topic in 2014, but we found several primary studies conducted after a systematic review was compiled; this systematic study focused on looking at the direct relationship between HTN and the incidence of OAG. This 
systematic study aims to further explore the mechanism and relationship between HTN and the incidence of OAG and to update the current results so that later it can become one of the primary considerations for providing screening and special attention to hypertensive patients who are at risk for OAG.

\section{METHODS}

\section{Literature search}

In this systematic review, a literature search will be conducted on 22 July 2020 from various databases, namely PUBMED, MEDLINE and EMBASE, using the keywords ((essential hypertension) OR (high blood pressures) OR (high blood pressure) OR (systemic hypertension) OR (hypertension) AND (Primary Open-Angle Glaucoma)). In addition, several valid studies outside the database will be included if they match the criteria.

\section{Study eligibility and screening criteriasd}

The study criteria that will be included in this systematic review are as follows: (1) publications in the last 15 years; (2) research design in the form of observational study; (3) the language used is in the form of Indonesian or English; (4) exposure in the form of systemic HTN ( $\geq 140 / 90 \mathrm{~mm} \mathrm{Hg}$ /currently taking antihypertensive drugs/self-reported) and (5) evaluated OAG as the outcome. The study criteria that will be excluded are as follows: (1) abstract not available; (2) full-text paper is not available and (3) wrong publication type (letter, newspaper, case reports and comment article).

Literature studies that match the eligibility criteria will be included, while those that do not match the criteria will be excluded with reasons. The conflicts in grouping the studies will be discussed together until a decision is reached. The results of the screening of literature studies will later be reported using the Preferred Reporting Items for Systematic Reviews and Meta-Analysis.

\section{Data collection}

Data collection will be carried out for all included studies. The data that will be collected include the following: (1) the main author; (2) year of publication; (3) the place where the research was conducted; (4) study design; (5) number of samples; (6) gender of samples; (7) mean/ range age of samples; (8) type of outcome and (9) incidence rate data from exposure and outcome.

Data collection was carried out by one reviewer (ATFZ) and then cross-checked by other reviewers (RN, AI, NW, FK and $A M A K G)$. If in the included literature study there is incomplete data, the reviewer will contact the author of the study; if the author does not respond, the study is then excluded with the reviewer's agreement.

\section{Quality assessment}

Quality assessment was carried out by two reviewers (ATFZ and AMAKG) using the Newcastle-Ottawa Scale. In a study with cross-sectional and case-control design, an assessment was carried out on the following three main aspects: selection, comparability and exposure. Meanwhile, in a study with a cohort design, the exposure aspect was replaced by assessing the outcome aspect. The assessment is done by discussing point by point, every point that has a low risk of bias, we will give one star, except for the aspect of compatibility, which allows for two stars. Studies with more stars show a better quality of the study.

\section{Statistical analysis}

The data obtained were processed using Review Manager V.5.3. We performed three meta-analyses intending to assess the association between age, gender and HTN with the incidence of OAG. The first meta-analysis was performed by including the incidence of glaucoma in the hypertensive and non-hypertensive groups to measure the risk ratio $(95 \% \mathrm{CI})$ of studies that met the criteria for inclusion in the quantitative analysis. In the first metaanalysis, we did a subgroup analysis by dividing the three groups of study based on the design of the study, which is a cross-sectional, case-control and cohort. The second meta-analysis was performed by including the mean age in glaucoma and non-glaucoma groups to measure the mean difference. The third meta-analysis done by inserting the glaucoma incidence rate for each group is gender male and female. The heterogeneity of the statistical analysis was seen from the $\mathrm{I}^{2}$ value.

\section{Publication bias}

Publication bias is evaluated subjectively by looking at the funnel plot. In addition, for situations where the heterogeneity was too high, Duval and Tweedie's trim-and-fill analysis was performed to recalculate effect sizes after removing all studies that could have caused publication bias. $^{11}$

\section{RESULTS}

\section{Literature search and result of screening}

In this systematic review, after searching literature studies from various databases, namely PUBMED, MEDLINE and EMBASE, using the keywords resulted in 3711 studies, which were then filtered according to predetermined criteria.

Before the screening, 52 duplicate studies were excluded. Furthermore, 3659 study titles and abstracts were screened independently by three reviewers ( $\mathrm{RN}$, ATFZ and AMAKG). A total of 3641 studies were excluded because they did not comply with predetermined criteria. The next 18 studies were screened by reading the text thoroughly. As a result, two studies were excluded because of incomplete data, incomplete data in the form of the incidence of glaucoma in the HTN group and the control group, so that the remaining 16 studies met the criteria with a total sample size of 72212 and were included for qualitative and quantitative analysis. Full details of search and filter results are presented in figure 1. 


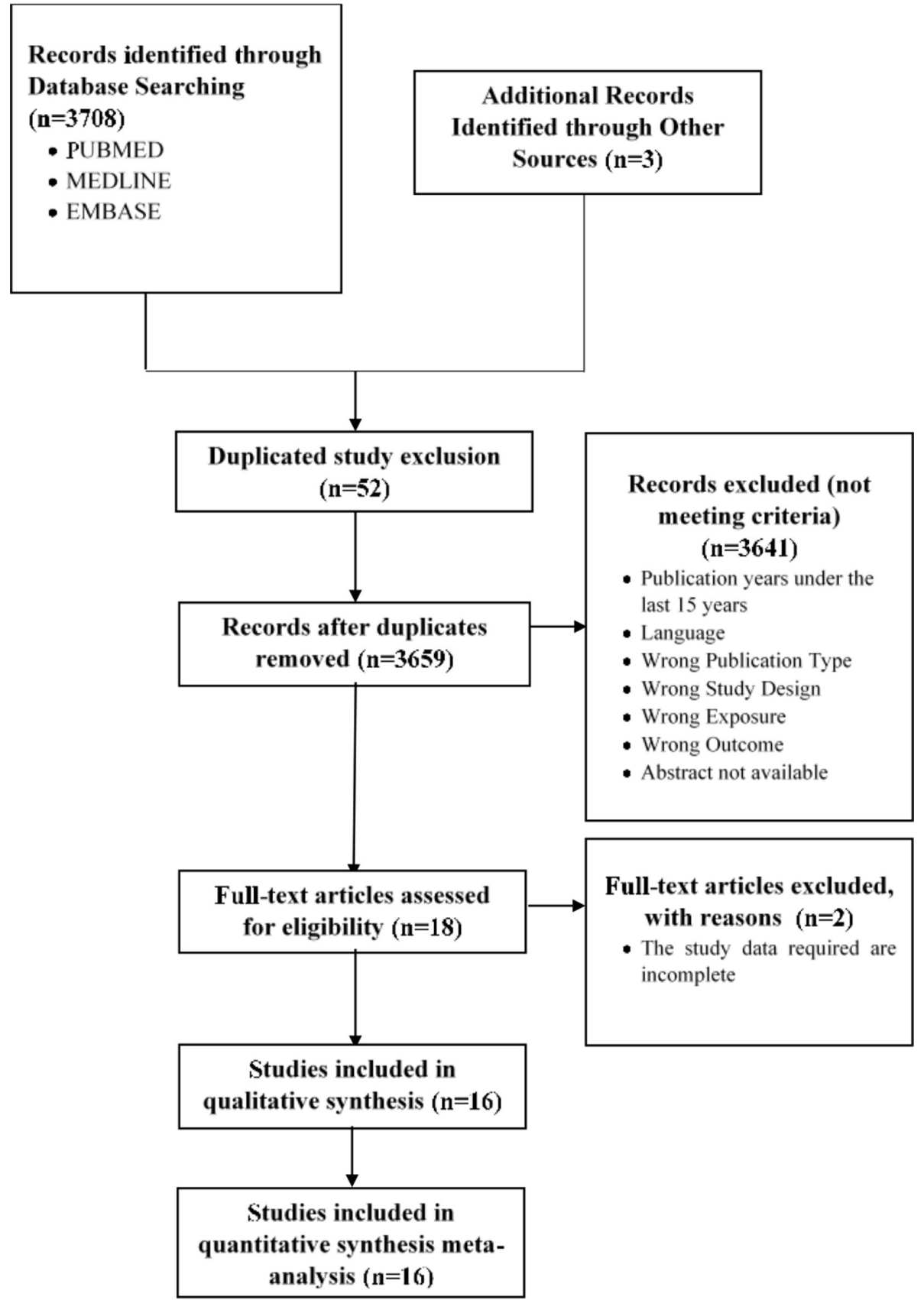

Figure 1 Preferred Reporting Items for Systematic Reviews and Meta-Analyses.

\section{Characteristics of the eligible studies}

The 16 included studies were primary studies conducted in 13 different countries with a total sample size of 72 212. Of the 16 studies, 11 used a cross-sectional design, 3 case-control and 2 cohorts. Twelve studies assessed the outcome of POAG, while the other four studies assessed the outcome of OAG. Full details of the characteristics of the included studies are presented in table 1.

\section{Quality assessment result}

The quality assessment of the 16 included studies was represented by the total stars obtained for each study from the range 0 to 9 . In general, the quality of the included studies was good; the lowest score was five stars in three studies, seven stars were found mostly in five studies, while the highest score was nine stars in two studies. The complete details of the quality assessment are presented in table 2 .

\section{Statistical test results (meta-analysis)}

Dichotomous data in the form of the incidence of OAG from each group (HTN and non-HTN) were collected from 16 included studies. Furthermore, the data are entered in a statistical test using the Review Manager V.5.3 application to see the risk ratio using the randomeffects model. During meta-analysis, we did a subgroup analysis by dividing the three groups of study based on the design of the study, which is a cross-sectional, casecontrol and cohort. The results showed a significant risk ratio of 1.69 (95\% CI 1.50 to 1.90$)$. Overall effect: $\mathrm{Z}=8.6$ 


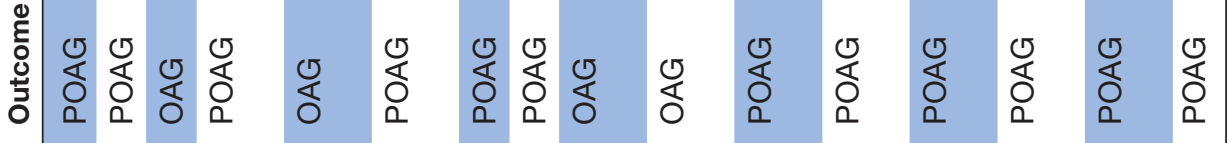

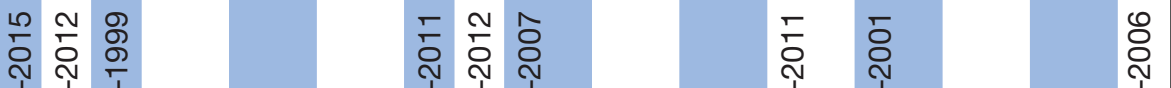

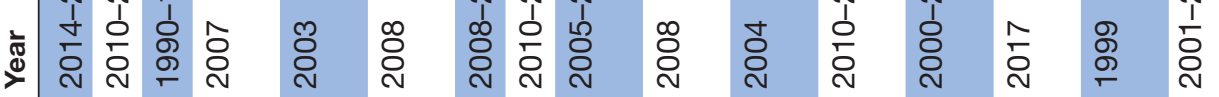

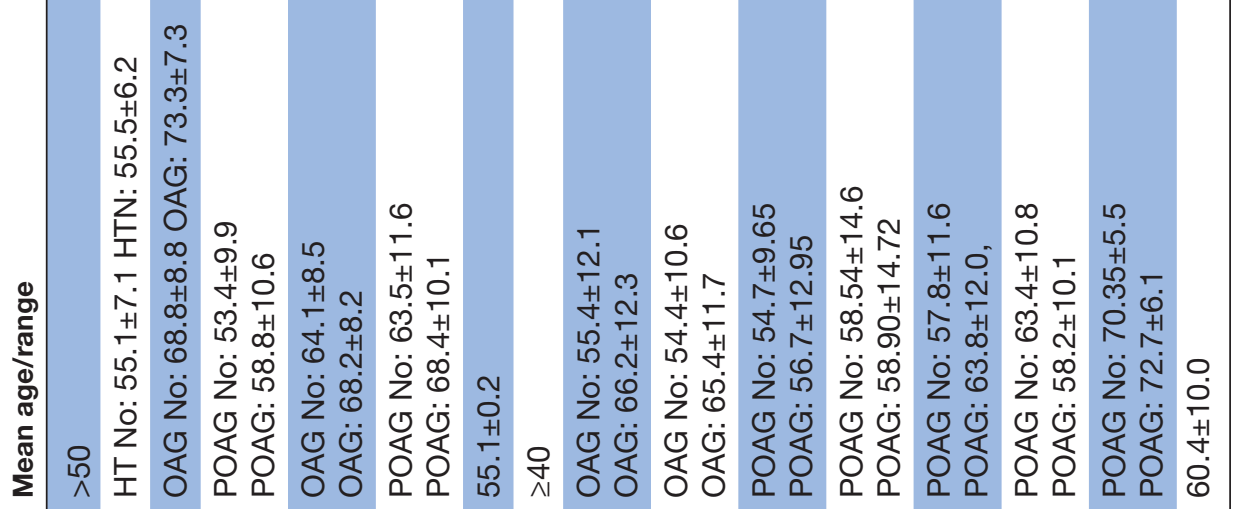

$\frac{8}{6}$

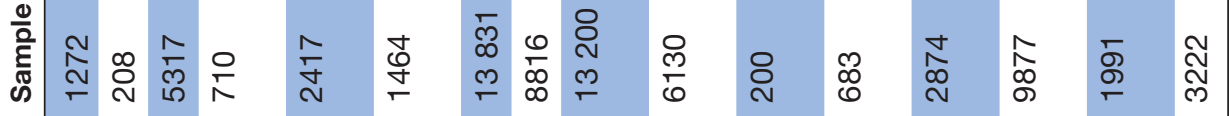

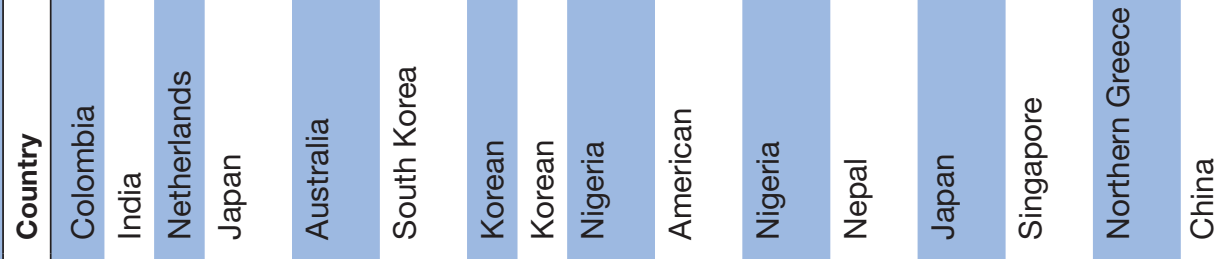

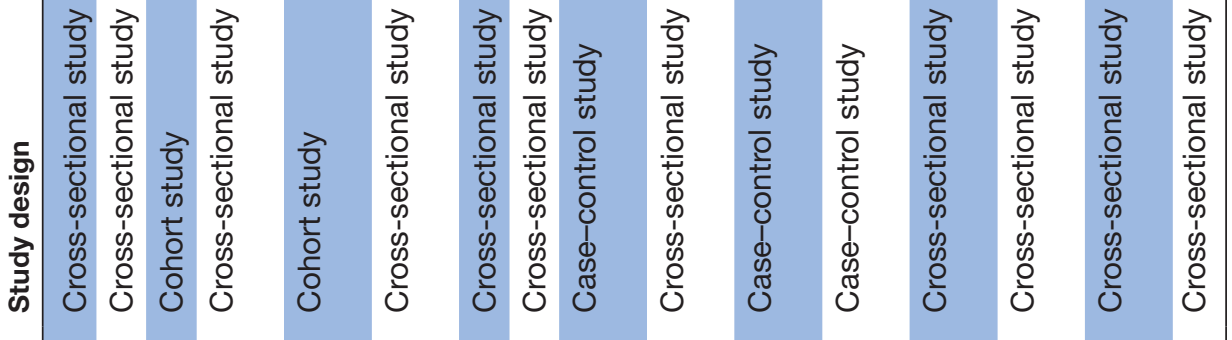
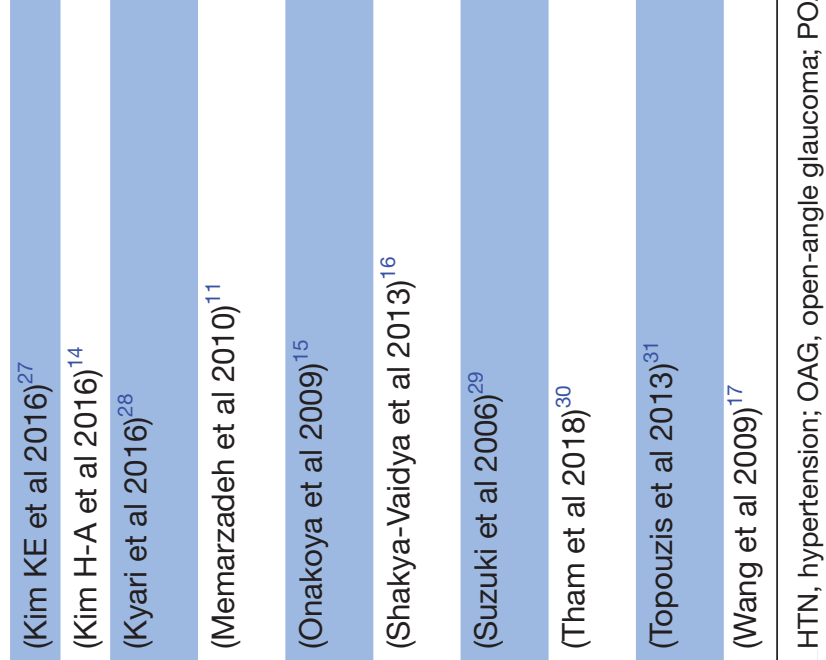
Table 2 Quality assessment result using Newcastle-Ottawa Scale

\begin{tabular}{|c|c|c|c|c|c|c|c|c|c|c|c|c|}
\hline \multirow[b]{2}{*}{ Study } & \multicolumn{5}{|c|}{$\mathbf{s}$} & \multicolumn{2}{|l|}{ C } & \multicolumn{4}{|c|}{$E / O$} & \multirow[b]{2}{*}{ Total } \\
\hline & 1 & 2 & 3 & 4 & SUM & 1 & SUM & 1 & 2 & 3 & SUM & \\
\hline Cantor et al (2018) & * & * & - & * & 3 & - & 0 & * & * & - & 2 & 5 \\
\hline Deb et al (2014) & - & - & - & * & 1 & * & 1 & * & * & * & 3 & 5 \\
\hline Hulsman (2007) & * & * & * & * & 4 & * & 1 & * & * & * & 3 & 8 \\
\hline Ishikawa et al (2011) & * & * & * & * & 4 & ** & 2 & * & * & * & 3 & 9 \\
\hline Kawasaki et al (2013) & * & * & * & * & 4 & ** & 2 & - & * & - & 1 & 7 \\
\hline Kim H-A (2016) & * & * & * & * & 4 & ** & 2 & * & * & * & 3 & 9 \\
\hline Kim (2012) & * & * & * & * & 4 & * & 1 & - & * & * & 2 & 8 \\
\hline Kim KE (2016) & * & * & * & * & 4 & ** & 2 & - & * & * & 2 & 8 \\
\hline Kyari et al(2016) & * & * & * & * & 4 & * & 1 & * & * & * & 3 & 8 \\
\hline Memarzadeh et al (2010) & * & * & * & * & 4 & * & 1 & * & * & - & 2 & 7 \\
\hline Onakoya et al (2009) & * & - & - & * & 2 & * & 1 & - & * & * & 2 & 5 \\
\hline Shakya-Vaidya et al (2013) & * & - & - & * & 2 & * & 1 & * & * & * & 3 & 6 \\
\hline Suzuki et al (2006) & * & * & * & * & 4 & ** & 2 & - & * & - & 1 & 7 \\
\hline Tham et al (2018) & * & * & * & * & 4 & ** & 2 & - & * & - & 1 & 7 \\
\hline Topouzis et al (2013) & * & * & * & * & 4 & * & 1 & - & * & * & 2 & 7 \\
\hline Wang et al (2009) & * & * & * & * & 4 & ** & 2 & * & * & * & 3 & 9 \\
\hline
\end{tabular}

C, comparability; E, exposure; O, outcome; S, selection.

$(\mathrm{p}<0.00001)$ and heterogeneity of $\tau^{2}=0.02 ; \chi^{2}=28.59$; $\mathrm{df}=15(\mathrm{p}=0.02) ; \mathrm{I}^{2}=48 \%$. These results are presented in the form of a forest plot in figure 2A.

Continuous data such as the mean age of each group (OAG and non-OAG) collected from 11 studies were included. Furthermore, the data are entered in a statistical test to see the mean difference using the random-effects model. The results showed a significant mean difference of 4.21 (95\% CI 0.70 to 7.72). Overall effect: $\mathrm{Z}=8.6$ $(\mathrm{p}<0.00001)$ and $\tau^{2}$ heterogeneity $=0.02 ; \chi^{2}=418.01 ; \mathrm{df}=10$ $(\mathrm{p}=0.02) ; \mathrm{I}^{2}=98 \%$. The results are presented in the form of forest plots in figure $3 \mathrm{~A}$.

Dichotomous data in the form of the incidence of OAG from each group (male and female) were collected from 12 included studies. Furthermore, the data are included in the statistical test to see the risk ratio using the fixed effect model. The results showed a significant risk ratio of 4.21 (95\% CI 1.20 to 1.41 ). Overall effect: $\mathrm{Z}=6.4 \quad(\mathrm{p}<0.00001)$ and heterogeneity $\chi^{2}=31.22 ; \mathrm{df}=11$ $(\mathrm{p}=0.001) ; \mathrm{I}^{2}=65 \%$. The results are presented in the form of forest plots in figure $4 \mathrm{~A}$.

\section{Publication bias}

The funnel plot in figure $2 \mathrm{~B}$ and figure $3 \mathrm{~B}$ shows the asymmetrical shape of the study distribution, indicating a low risk of publication bias in this meta-analysis. However, the funnel plot in figure $4 \mathrm{~B}$ shows the asymmetrical shape of the study distribution, indicating a high risk of publication bias in this meta-analysis, with a cumulative subjective assessment.

\section{DISCUSSION}

The results of the meta-analysis showed that people with systemic HTN had a significantly 1.71-fold risk of developing glaucoma compared with non-hypertensive people (1.71 (95\% CI 1.58 to 1.85)) with minimal publication bias assessed subjectively using a funnel plot. This is in line with various previous primary studies which reported a significant relationship between systemic HTN and the incidence of OAG. ${ }^{11}{ }^{13-17}$ A meta-analysis assessing the effect of intraocular and $\mathrm{BP}$ reported that a $10 \mathrm{~mm} \mathrm{Hg}$ increase in systolic BP resulted in an increase in IOP by $0.26 \mathrm{~mm} \mathrm{Hg}$, whereas an increase in diastolic BP by $5 \mathrm{~mm} \mathrm{Hg}$ increased IOP by $0.17 \mathrm{~mm}$ $\mathrm{Hg}^{12}$

The results of the second meta-analysis showed that the average age of patients with OAG was higher with a mean difference result (4.21 (95\% CI 0.7 to 7.72$)$ ). The results of another meta-analysis showed that the female gender had a higher risk of experiencing OAG with the result of a risk ratio (1.3 (95\% CI 1.2 to 1.41$)$ ). This shows that in addition to HTN, age and gender also contribute to the incidence of OAG.

High BP can increase IOP through two mechanisms, first, an increase in the production of aqueous humour, which is caused by an increase in capillary pressure in the ciliary body, thereby increasing the intravascular pressure and IOP gradient; second, decreasing the absorption of aqueous humour due to an increase in episclera venous pressure which obstructs return flow of aqueous humour. ${ }^{12}{ }^{18}$ Through this mechanism, HTN increases the IOP, which causes mechanical stress 


\section{A}
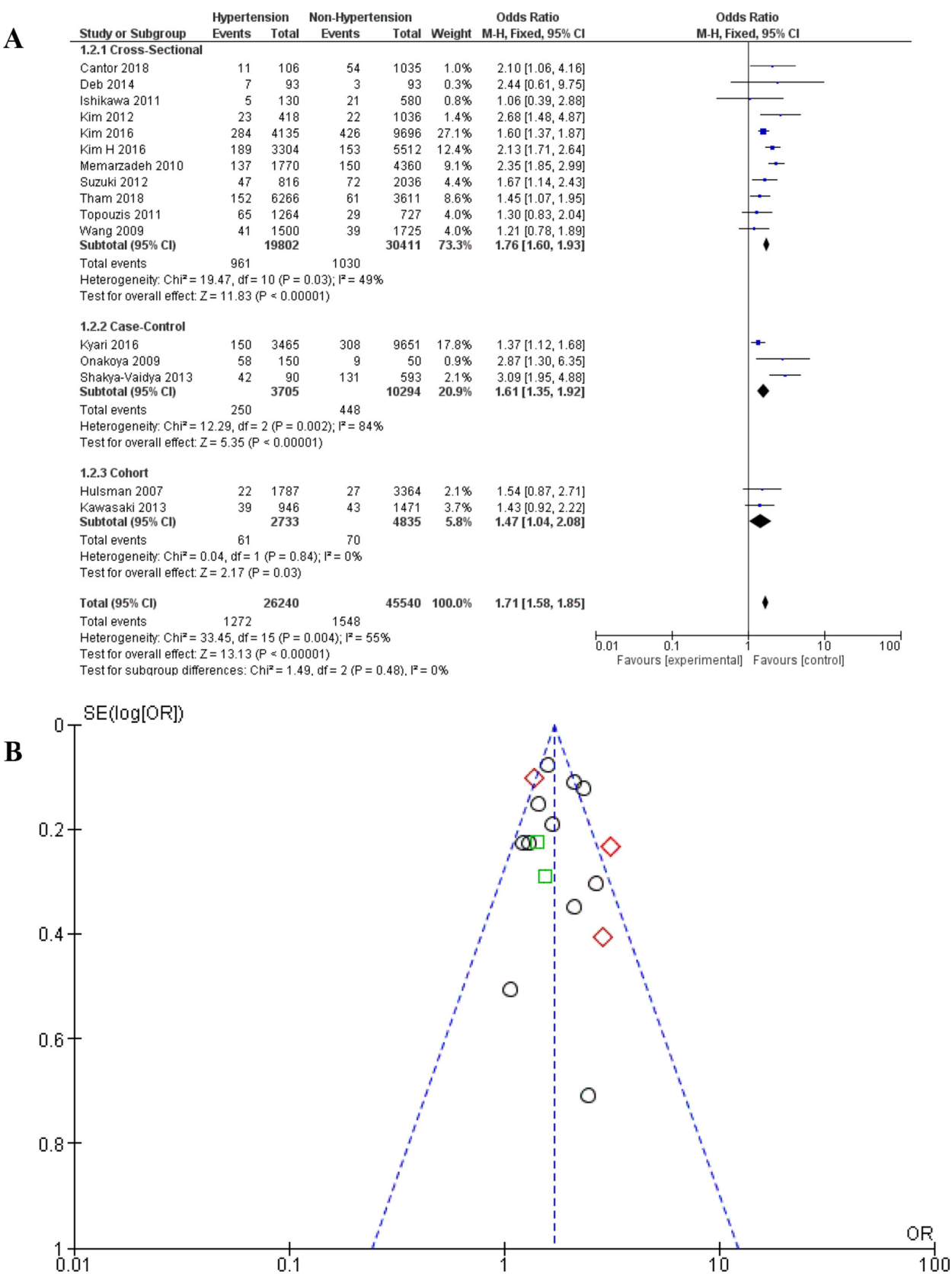

○ C Cross-Sectional $\diamond$ Case-Control $\square$ Cohort

Figure 2 (A) Forest plot subgroup meta-analysis (hypertension vs non-hypertension) on the incidence of OAG and (B) funnel plot meta-analysis (hypertension vs non-hypertension) on the incidence of OAG. OAG, open-angle glaucoma.

on the lamina cribrosa in the posterior segment of the eye and results in damage to the axons and optic nerve fibres, thus developing OAG. In addition, Cantor et $a t^{\ominus 131920}$ reported that in hypertensive patients, glaucoma damage could occur due to the ischaemic optic nerve or RGCs due to decreased perfusion pressure. Although eye blood flow has an autoregulation process to ensure adequate irrigation of the eye tissue, changes in the production of endothelin-1 levels in patients with HTN lead to disruption of the vascular dysfunction process that can interfere with this process. In a cohort study conducted by Kawasaki et al, for 10 years, it has been reported that HTN causes a narrowing of the calibre of the central retinal artery (CRA), which results in impaired flow to the eye, especially in the ocular nerve head and lamina cribrosa and triggers glaucoma. $^{21}$

Memarzadeh et al reported that in younger patients HTN exert a protective effect by increasing OPP. However, Memarzadeh et al ${ }^{11}$ giving the exception of older patients, this protective effect is lost as a result of the morphological changes in the blood vessels caused by prolonged systemic HTN and resulting in impaired oxygen and nutrient supply. In systemic hypertensive 
A

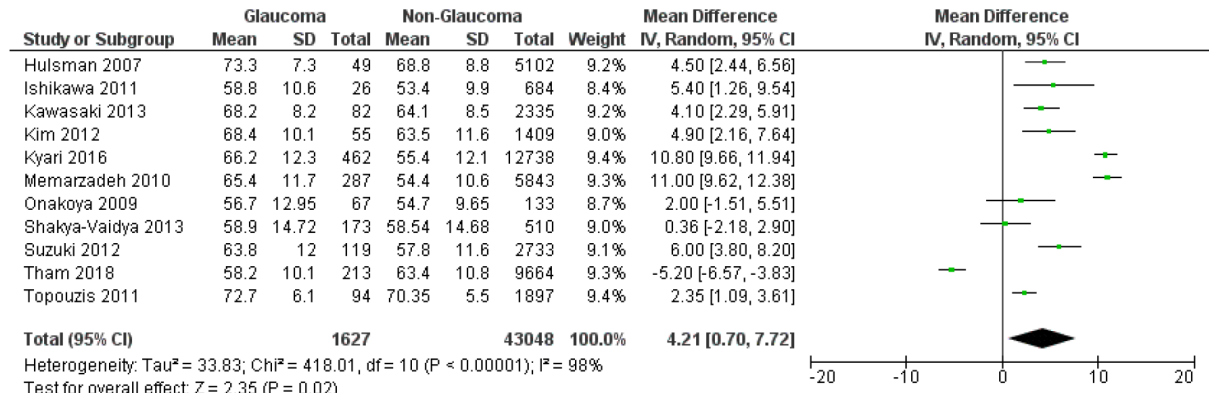

Test for overall effect $Z=235(P=0.02)$

B

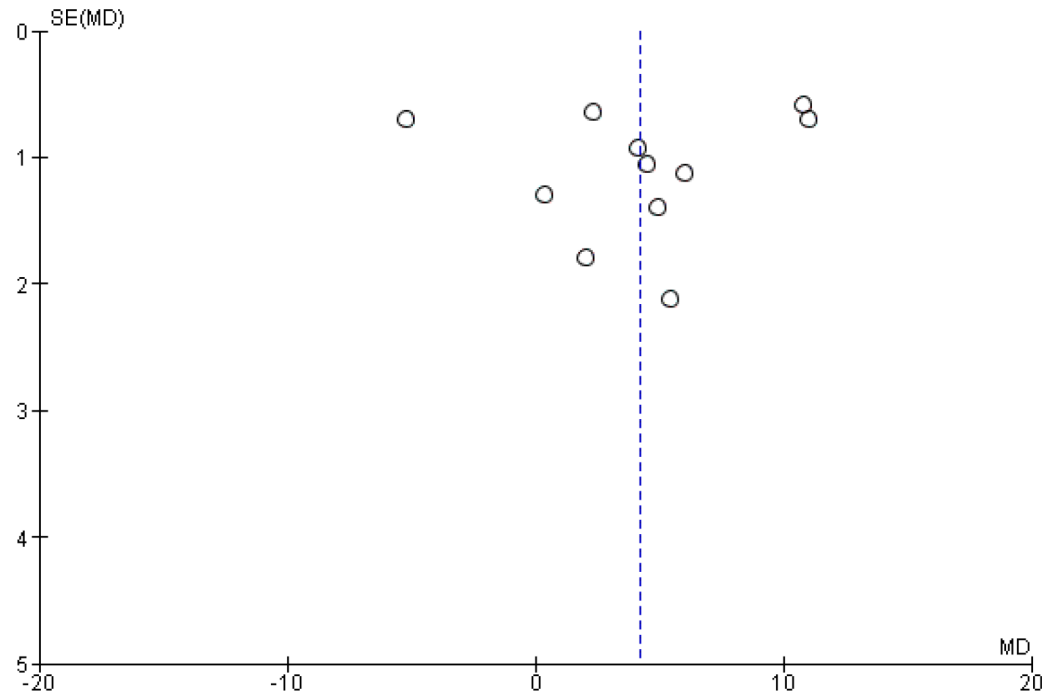

Figure 3 (A) Forest plot meta-analysis mean age on glaucoma vs non-glaucoma groups and (B) funnel plot meta-analysis mean age on glaucoma vs non-glaucoma groups. Each Black circle is a study that is distributed based on the $\mathrm{x}$-axis: Risk ratio and the y-axis: SE of RR. So, one black circle represents one study.

patients, a chronic increase in BP is at risk of causing arteriosclerosis, changes in precapillary arteriolar size leading to increased resistance to blood flow and resulting in decreased perfusion in the posterior segment of the eye, thereby counteracting the protective effect prevailing at younger ages. ${ }^{22}$

In summary, the relationship between HTN as a risk factor for glaucoma has several mechanisms: (1) the presence of mechanical stress on the lamina cribrosa as a result of an increase in IOP caused by an increase in the production of aqueous humour by an increase in blood flow in the ciliary body and a decrease in the absorption of aqueous humour due to an increase in episclera venous pressure; (2) autoregulation disorders resulting from an imbalance in endothelin-1 levels; (3) narrowing of the calibre of the CRA due to chronic HTN, which causes blood flow to the eyes and (4) the incidence of atherosclerosis in chronic HTN, which also results in narrowing of the calibre of the CRA (figure 5). ${ }^{17-20} 22$

In contrast to the previous results, Ishikawa $e t a l^{23}$ reported that a lower diastolic blood pressure (DBP; $\leq 58 \mathrm{~mm} \mathrm{Hg})$ had an OR of $2.08(1.21-5.45)$ than normal DBP to the incidence of OAG. Correspondingly, Memarzadeh $e t$ al also reported that the lower diastolic pressure $(\leq 60 \mathrm{~mm} \mathrm{Hg})$ has an OR of 1.90 (1.1-3.0). Hulsman et al also reported that a decrease in diastolic perfusion pressure showed a significant association with the incidence of htOAG (high tension OAG) with IOP $>21 \mathrm{~mm} \mathrm{Hg}$. This is closely related to the mean ocular perfusion pressure (MOPP), which is the pressure gradient between mean arterial pressure (MAP) and IOP. In the formula $\left(\mathrm{MOPP}=\frac{2}{3} \mathrm{MAP}-\mathrm{IOP}\right)$, we can conclude that MAP has a positive $(+)$ relationship with MOPP. In contrast, the IOP has a (-) relationship with MOPP. In addition, from the MAP formula $\left(\frac{2 D B P+1 S B P}{3}\right.$ ), it can be seen that DBP has a $2 \times$ more effect than systolic in the MAP calculation. This could explain why a decrease in DBP can to have an effect on reducing perfusion pressure in the eye, which results in the risk of OAG. These results lead to the assumption that people who have unstable DBP, either high DBP or low DBP, are both able to increase the risk of OAG events. However, none of the included studies reported a specific association between systolic BP and the incidence of OAG. ${ }^{11}{ }^{13}$ However, none of the included studies reported a specific association between systolic $\mathrm{BP}$ and the incidence of OAG.

Apart from all the previous explanations, we realise that there are still many shortcomings in this study, one of which is because it does not review the treatment for HTN, this is because the included study did not report 
A

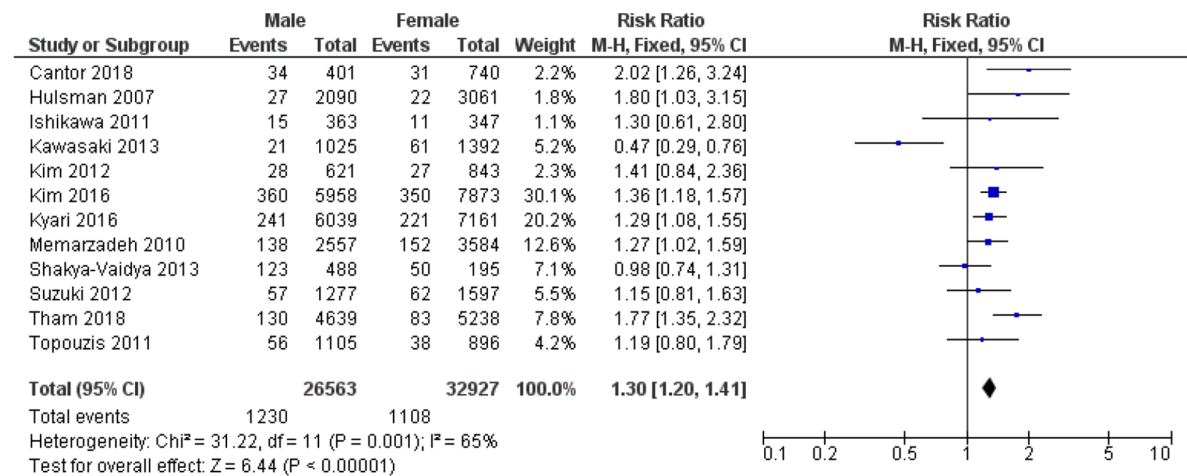

B

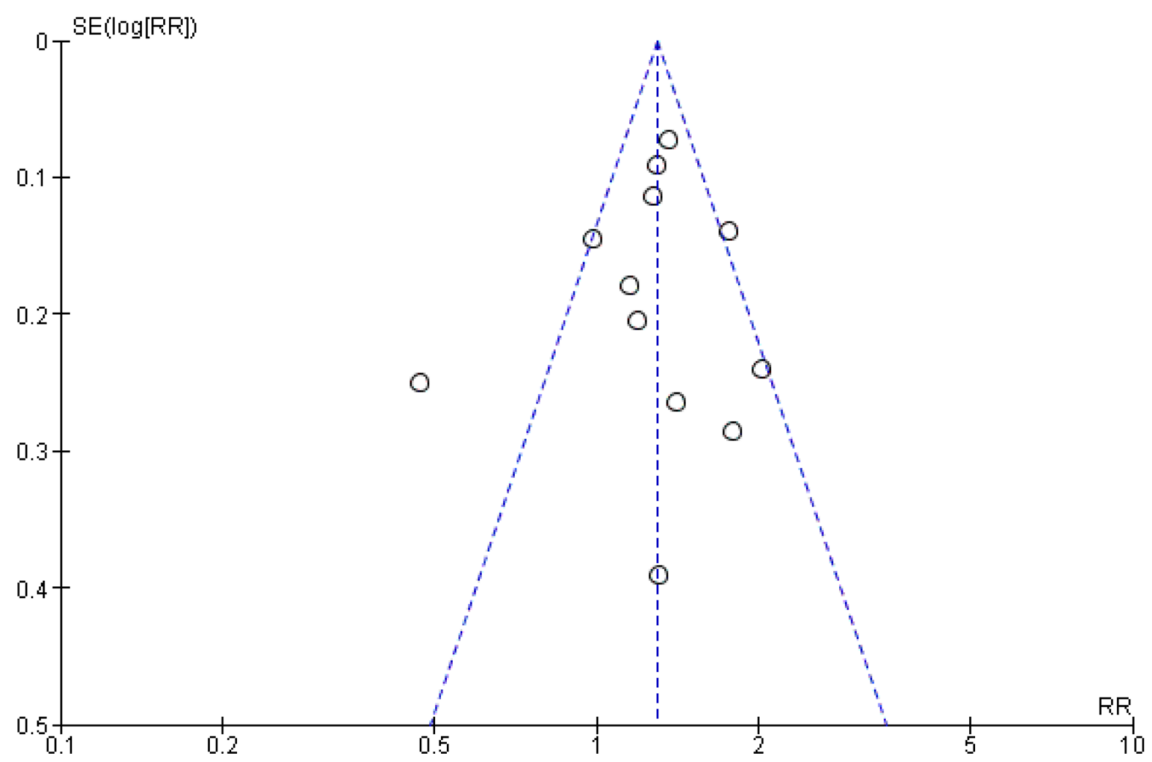

Figure 4 (A) Forest plot subgroup meta-analysis (gender) on the incidence of OAG and (B) funnel plot meta-analysis (gender) on the incidence of OAG. OAG, open-angle glaucoma. Each Black circle is a study that is distributed based on the $\mathrm{x}$-axis: Risk ratio and the $y$-axis: SE of RR. So, one black circle represents one study.

on this matter, so further research is still needed. From these results, we recommend conducting clinical trials on the effect of antihypertensive drugs in preventing and slowing the progression of OAG.

\section{CONCLUSION}

Based on this systematic review, it can be concluded that HTN increases the risk of OAG. However, several studies explain that low DBP also increases the risk of OAG, so there is a U-shaped effect between DBP and OAG.

The results of this systematic review are an update of existing results with a focus on the relationship between HTN and OAG, which are expected to be the basis of clinical practice by paying special attention to hypertensive patients who are at risk of developing OAG.

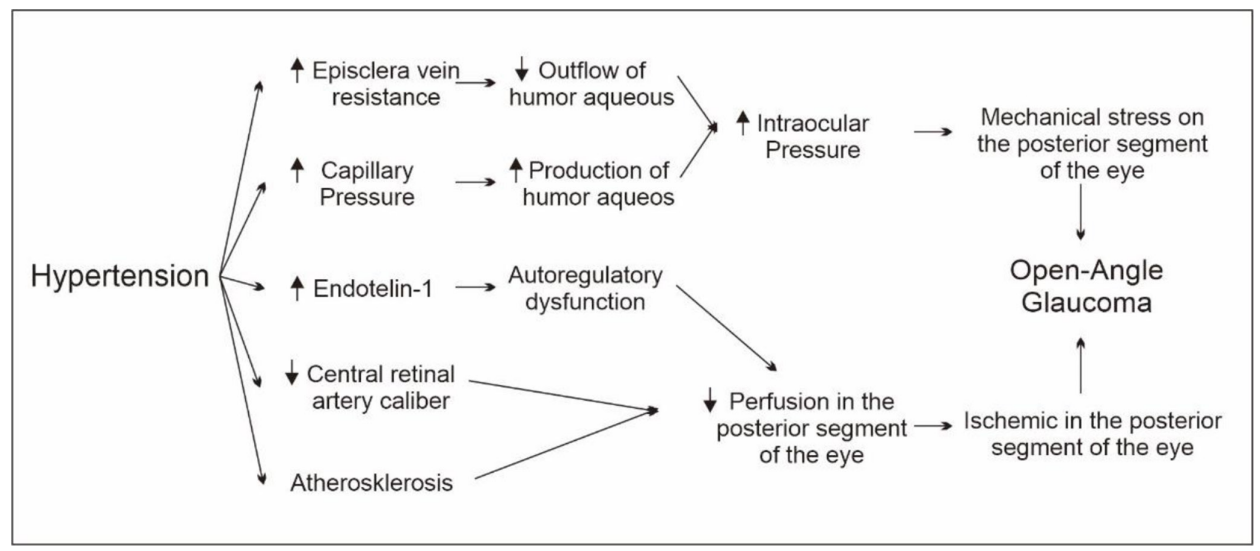

Figure 5 The mechanism of the role of hypertension on the risk of open-angle glaucoma. 
Acknowledgements We thank those who have helped in the process of compiling this review; Department of Ophthalmology, Hasanuddin University and Faculty of Medicine, Hasanuddin University. To the team who are always enthusiastic in compiling this review, to Indah Nurul Khairunnisa in the process of perfecting the use of language in this review.

Contributors RN had the same contribution as AT, both of whom were involved in all stages, drafting the concept, determining eligibility criteria, literature searching, study screening, data collection, quality assessment, statistical analysis, interpretation the result and draft writing. Al and NW were involved in drafting the concept and critical revision of the article. FK was involved in drafting the article and final approval of the version to be published. AM was involved in the study screening process, data collection and quality assessment. In the process of making this article, the second author (corresponding) has equally contributed with first author.

Funding The authors have not declared a specific grant for this research from any funding agency in the public, commercial or not-for-profit sectors.

Competing interests None declared.

Patient consent for publication Not applicable.

Ethics approval The study in question was not submitted to local ethical committee for approval since it involved a retrospective chart review of patients from existing literature and qualifies for exempt status under human subject regulations in our opinion.

Provenance and peer review Not commissioned; externally peer reviewed.

Data availability statement № data are available.

Open access This is an open access article distributed in accordance with the Creative Commons Attribution Non Commercial (CC BY-NC 4.0) license, which permits others to distribute, remix, adapt, build upon this work non-commercially, and license their derivative works on different terms, provided the original work is properly cited, appropriate credit is given, any changes made indicated, and the use is non-commercial. See: http://creativecommons.org/licenses/by-nc/4.0/.

ORCID iD

Ahmad Taufik Fadillah Zainal http://orcid.org/0000-0002-3480-7692

\section{REFERENCES}

1 Kementerian Kesehatan RI. INFODATIN Kesehatan RI Situasi DAN Analisis Glaukoma. Kementerian kesehatan RI, 2014.

2 Chung HJ, Hwang HB, Lee NY. The association between primary open-angle glaucoma and blood pressure: two aspects of hypertension and hypotension. Biomed Res Int 2015;2015:1-7 https://www.hindawi.com/journals/bmri/2015/827516/

3 Kwon $\mathrm{YH}$, Fingert JH, Kuehn $\mathrm{MH}$, et al. Primary open-angle glaucoma. N Engl J Med 2009;360:1113-24.

4 Weinreb RN, Aung T, Medeiros FA. The pathophysiology and treatment of glaucoma: a review. JAMA 2014;311:1901-11.

5 Baig NB, Cheng GPM, Lam JKM, et al. Intraocular pressure profiles during femtosecond laser-assisted cataract surgery. J Cataract Refract Surg 2014;40:1784-9.

6 Burgoyne CF, Downs JC, Bellezza AJ, et al. The optic nerve head as a biomechanical structure: a new paradigm for understanding the role of IOP-related stress and strain in the pathophysiology of glaucomatous optic nerve head damage. Prog Retin Eye Res 2005;24:39-73.

7 Lee I-T, Wang J-S, Fu C-P, et al. The synergistic effect of inflammation and metabolic syndrome on intraocular pressure: a cross-sectional study. Medicine 2017;96:e7851.

8 Irum S, Malik AM, Saeed M. Mean intraocular pressure in hypertensive adults. Pakistan Armed Forces Medical Journal 2015;65:73-6.
9 He Z, Vingrys AJ, Armitage JA, et al. The role of blood pressure in glaucoma. Clin Exp Optom 2011;94:133-49.

10 Quigley HA, West SK, Rodriguez J, et al. The prevalence of glaucoma in a population-based study of Hispanic subjects: Proyecto VER. Arch Ophthalmol 2001;119:1819-26.

11 Memarzadeh F, Ying-Lai M, Chung J. And open-angle glaucoma: the Los Angeles Latino eye study. Invest Ophthalmol Vis Sci 2010;51:2872.

12 Zhao D, Cho J, Kim MH, et al. The association of blood pressure and primary open-angle glaucoma: a meta-analysis. Am J Ophthalmol 2014;158:615-27.

13 Cantor E, Méndez F, Rivera C, et al. Blood pressure, ocular perfusion pressure and open-angle glaucoma in patients with systemic hypertension. Clin Ophthalmol 2018;12:1511-7.

$14 \mathrm{Kim} \mathrm{H-A}$, Han K, Lee Y-A, et al. Differential association of metabolic risk factors with open angle glaucoma according to obesity in a Korean population. Sci Rep 2016;6:38283.

15 Onakoya AO, Ajuluchukwu JN, Alimi HL. Primary open angle glaucoma and intraocular pressure in patients with systemic hypertension. East Afr Med J 2009;86:74-8.

16 Shakya-Vaidya S, Aryal UR, Upadhyay M, et al. Do noncommunicable diseases such as hypertension and diabetes associate with primary open-angle glaucoma? insights from a casecontrol study in Nepal. Glob Health Action 2013;6:22636.

17 Wang S, Xu L, Jonas JB, et al. Major eye diseases and risk factors associated with systemic hypertension in an adult Chinese population: the Beijing eye study. Ophthalmology 2009;116:2373-80.

18 Levine RM, Yang A, Brahma V, et al. Management of blood pressure in patients with glaucoma. Curr Cardiol Rep 2017;19:109.

19 Moore D, Harris A, Wudunn D, et al. Dysfunctional regulation of ocular blood flow: a risk factor for glaucoma? Clin Ophthalmol 2008;2:849-61.

20 Resch H, Garhofer G, Fuchsjäger-Mayrl G, et al. Endothelia dysfunction in glaucoma. Acta Ophthalmol 2009;87:4-12.

21 Kawasaki R, Wang JJ, Rochtchina E, et al. Retinal vessel caliber is associated with the 10-year incidence of glaucoma: the blue Mountains eye study. Ophthalmology 2013;120:84-90.

22 Hayreh SS. Role of nocturnal arterial hypotension in the development of ocular manifestations of systemic arterial hypertension. Curr Opin Ophthalmol 1999;10:474-82.

23 Ishikawa M, Sawada Y, Sato N, Sawada, Sato Y, et al. Risk factors for primary open-angle glaucoma in Japanese subjects attending community health screenings. Clin Ophthalmol 2011;5:1531-7.

24 Deb AK, Kaliaperumal S, Rao VA, et al. Relationship between systemic hypertension, perfusion pressure and glaucoma: a comparative study in an adult Indian population. Indian J Ophthalmol 2014;62:917.

25 Hulsman CAA, Pressure B, Stiffness A. And open-angle glaucoma: the Rotterdam study. Arch Ophthalmol 2007;125:805.

26 Kim M, Kim T-W, Park KH, et al. Risk factors for primary openangle glaucoma in South Korea: the Namil study. Jpn J Ophthalmol 2012;56:324-9.

27 Kim KE, Kim MJ, Park KH, et al. Prevalence, awareness, and risk factors of primary open-angle glaucoma. Ophthalmology 2016;123:532-41.

28 Kyari F, Abdull MM, Wormald R, et al. Risk factors for open-angle glaucoma in Nigeria: results from the Nigeria national blindness and visual impairment survey. BMC Ophthalmol 2016;16:78.

29 Suzuki Y, Iwase A, Araie M, et al. Risk factors for open-angle glaucoma in a Japanese population: the Tajimi study. Ophthalmology 2006;113:1613-7.

30 Tham Y-C, Lim S-H, Gupta P, et al. Inter-Relationship between ocular perfusion pressure, blood pressure, intraocular pressure profiles and primary open-angle glaucoma: the Singapore epidemiology of eye diseases study. Br J Ophthalmol 2018;102:1402-6.

31 Topouzis F, Wilson MR, Harris A, et al. Association of open-angle glaucoma with perfusion pressure status in the Thessaloniki eye study. Am J Ophthalmol 2013;155:843-51. 